\title{
Computational Singular Perturbation Analysis of Super- knock in SI Engines
}

\author{
Mohammed Jaasim, Efstathios-Al. Tingas, Francisco E. Hernández Pérez, Hong G. Im \\ Clean Combustion Research Center, King Abdullah University of Science and Technology
}

\begin{abstract}
Pre-ignition engine cycles leading to super-knock were simulated with a 48 species skeletal iso-octane mechanism to identify the dominant reaction pathways that are present in super-knock. To mimic pre-ignition, a deflagration front was generated via a hot spot that is placed over the piston at close proximity to the end-wall. Computational singular perturbation (CSP) was used to analyze the chemical dynamics at various in-cylinder locations: a point at the center of the cylinder where the deflagration front consumes the air/fuel mixture and two points located at $3 \mathrm{~mm}$ from the end-wall where super-knock and mild knock occur. The CSP analysis of the point at the center of the cylinder reveals weak two-stage ignition-like dynamics with a short second stage. At the other points, a pronounced two-stage ignition is displayed with a long second stage. A distinct contribution of formaldehyde $\left(\mathrm{CH}_{2} \mathrm{O}\right)$ at the second stage of ignition that adds to fast explosive modes in the super-knock points is not observed in the point at the center. A comparison between knock and super-knock analysis indicates that a similar set of reactions is responsible for the abnormal behavior but the fast explosive time scales are comparatively slower for knock, indicating lower reactivity, which results in the reduced intensity of knock. The analyzed results decoded important reactions responsible for the occurrence of super-knock. Keywords: Computational singular perturbation; Pre-ignition; Super-knock
\end{abstract}




\section{Introduction}

To achieve clean and efficient operation, modern spark ignition (SI) engines are downsized to reduce fuel consumption and emissions [1]. To compensate for the reduced displacement, the intake pressure is boosted to achieve the desired power, resulting in unwanted premature auto-ignition, known as pre-ignition, of the reactant charge prior to spark timing. Preignition sometimes lead to the occurrence of sharp pressure peaks and high frequency pressure oscillations, called super-knock. Due to their stochastic nature of pre-ignition and super-knock [2], their prediction and preventions of pre-ignition and super-knock have long been a serious technical challenge, in further improvement of efficiency in SI engines [3].

Pre-ignition and super-knock depend on available in-cylinder reactive local hot spots and mixture characteristics [4]. The fundamental questions on this subject are twofold. The first is concerning the source of pre-ignition. External sources such as carbon particles attached to engine walls and oil droplets that escape from the liner, as well as their composition are reported as the dominant source of pre-ignition [5-7]. The second question is about how the pre-ignition event develops into super-knock. Once the pre-ignition forms an initial flame front, the flame propagation increases the temperature and pressure of the end-gas mixture and may cause a secondary auto-ignition in another reactive hot spot, leading to detonation [8]. The amplitude of the pressure pulse generated depends on the rate of change of heat release at the hot spot.

Various direct numerical simulation (DNS) studies with hot spots [4, 8] have been performed to understand super-knock. All these studies focused on bulk mixture properties, gradients of temperature, ignition delay sensitivity and heat release to characterize the effect of the hot spot and resulting auto-ignition front. However, to the author's knowledge there is 
limited information about the chemical characteristics of the system such as the dominant reaction pathways and gas species that cause super-knock.

Recognizing the general interest and relevance of pre-ignition and super-knock, full-cycle engine simulations were performed by the authors recently, which successfully reproduced the occurrence of super-knock events depending on the timing of the pre-ignition event [9]. To gain further insights, the simulation data are further analyzed in order to understand the detailed chemical characteristics inside the local unburned mixture that develops super-knock. To this end, detailed computational singular perturbation (CSP) analysis is performed at various selected

locations to elucidate the reactions related to super-knock. Since the source of pre-ignition is highly stochastic and not known clearly, the objective of the study is not to identify the source of pre-ignition; instead the study is focused on the chemical behavior of unburned mixture that triggers super-knock after pre-ignition. In what follows, the CSP methodology is described, results are discussed, and concluding remarks are provided.

\section{Problem Specification}

The main scope of this paper is the analysis of the existing SI engine simulation data reproducing a super-knock event [9]. Fig. 1 shows the geometry of the engine used in simulations and the cut-sections of the mesh generated for the study. The specifications and operating conditions selected for the study are provided in Table 1. A base mesh size of $4 \mathrm{~mm}$ was used initially to generate the mesh, which was further refined with adaptive mesh refinement (AMR) based on the temperature difference $(5 \mathrm{~K})$ between adjacent cells. The Kelvin Helmholtz/Rayleigh Taylor spray breakup model was used to represent the spray break-up behavior $[10,11]$. The droplets were grouped into parcels and injected with each parcel 
containing 50 droplets. Collision between droplets was modeled using the no-time counter algorithm [12]. The radius of the evaporating droplet is calculated using the Frossling correlation. The droplets that impinge on the walls during injection form a wall film, which was accounted for with a wall film model [13]. Physical properties of iso-octane were used to represent the fuel spray behavior. A multi-zone approach, based on a well-stirred reactor model, was used to capture endgas auto-ignition coupled with the G-equation model to describe govern the pre-ignition flame propagation. In the multizone approach the cells are grouped based on temperature and equivalence ratio bins of $5 \mathrm{~K}$ and 0.05 increments $[14,15]$. The in-cylinder simulations were performed using the Reynolds-averaged Navier-Stokes (RANS) method in conjunction with the renormalization group (RNG) k-epsilon model [16]. The heat loss from walls was calculated using the model developed by Han and Reitz [17]. The reader may refer to [9] for detailed information on the models used in the study.

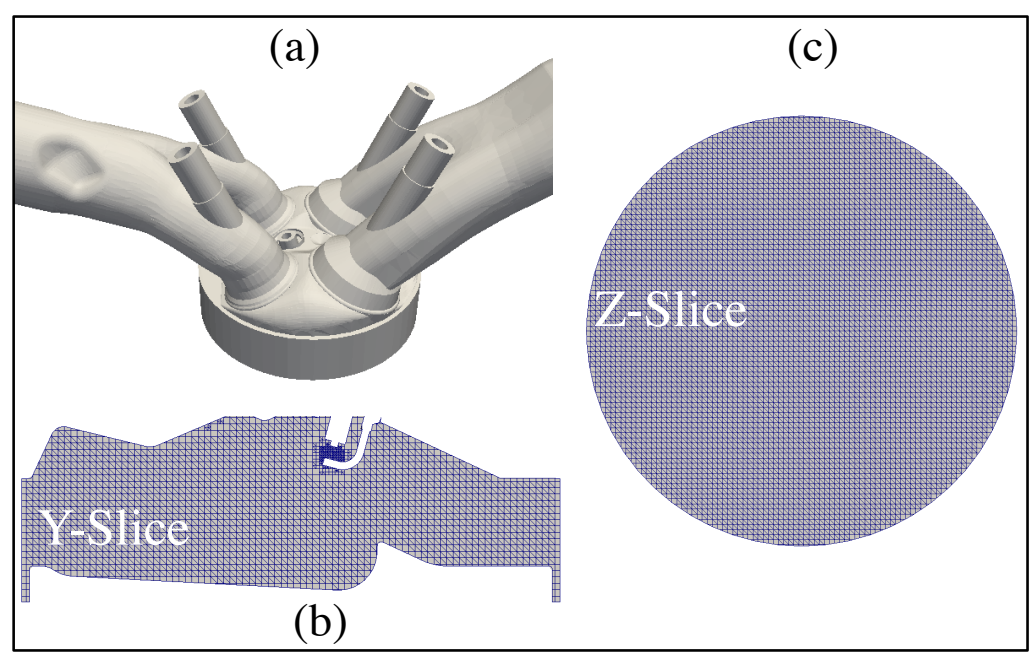

Fig. 1. (a) Geometry of the SI engine, (b) Y-slice with mesh at mid-section of cylinder, (c) Zslice with mesh at $8 \mathrm{~mm}$ from spark plug.

In the simulation cases under study, a pre-ignition event was represented by a hot spot of $1 \mathrm{~mm}$ radius with a temperature of $2000 \mathrm{~K}$. The temperature of $2000 \mathrm{~K}$ was selected to initiate the pre- 
Table 1. Engine specifications and operating conditions for the study.

\begin{tabular}{llll}
\hline Specifications & Values & Operating conditions & Values \\
\hline Bore & $85 \mathrm{~mm}$ & RPM & 1200 \\
Stroke & $90 \mathrm{~mm}$ & Intake temperature & $300 \mathrm{~K}$ \\
Connecting rod length & $138 \mathrm{~mm}$ & Intake pressure & $2 \mathrm{bar}$ \\
Compression ratio & 9.5 & Global equivalence ratio & 1 \\
Valves & 2 -intake,2-exhaust valves & Fuel & iso-octane \\
Spark plug energy & $40 \mathrm{~mJ}$ & Spark time & 5 CAD aTDC \\
\hline
\end{tabular}

ignition front immediately after its introduction in the cylinder. The hot spot was placed over the piston close to the liner and was initiated at $-20 \mathrm{CAD}$ of TDC. A deflagration front was subsequently generated from the hot spot and propagates into the mixture. Three spatial locations were selected for the CSP analysis (see Fig. 2). Point A is located at center of the cylinder where no pressure peaks or oscillations are observed. The deflagration flame consumes the fuel at point $\mathrm{A}$ and hence no auto-ignition is observed. Points $\mathrm{B}$ and $\mathrm{C}$ are located at $3 \mathrm{~mm}$ from the end-wall opposite to the location of the pre-ignition hot spot, and develop super-knock with high pressure peaks and oscillations. The two points were selected based on their unique behavior so that the CSP analysis could reveal the dominant reactions that contribute to superknock at these two points. The pressure histories at points A, B and C are shown in Fig. 2, exhibiting intense pressure oscillations at points B and C.

\section{Computational Diagnostic Tools}

Computational singular perturbation (CSP) is an algorithmic method of asymptotic analysis that has been widely used for the investigation of various combustion and biological processes. The reader may refer to $[18,19]$ for a more detailed description of the method. In the 


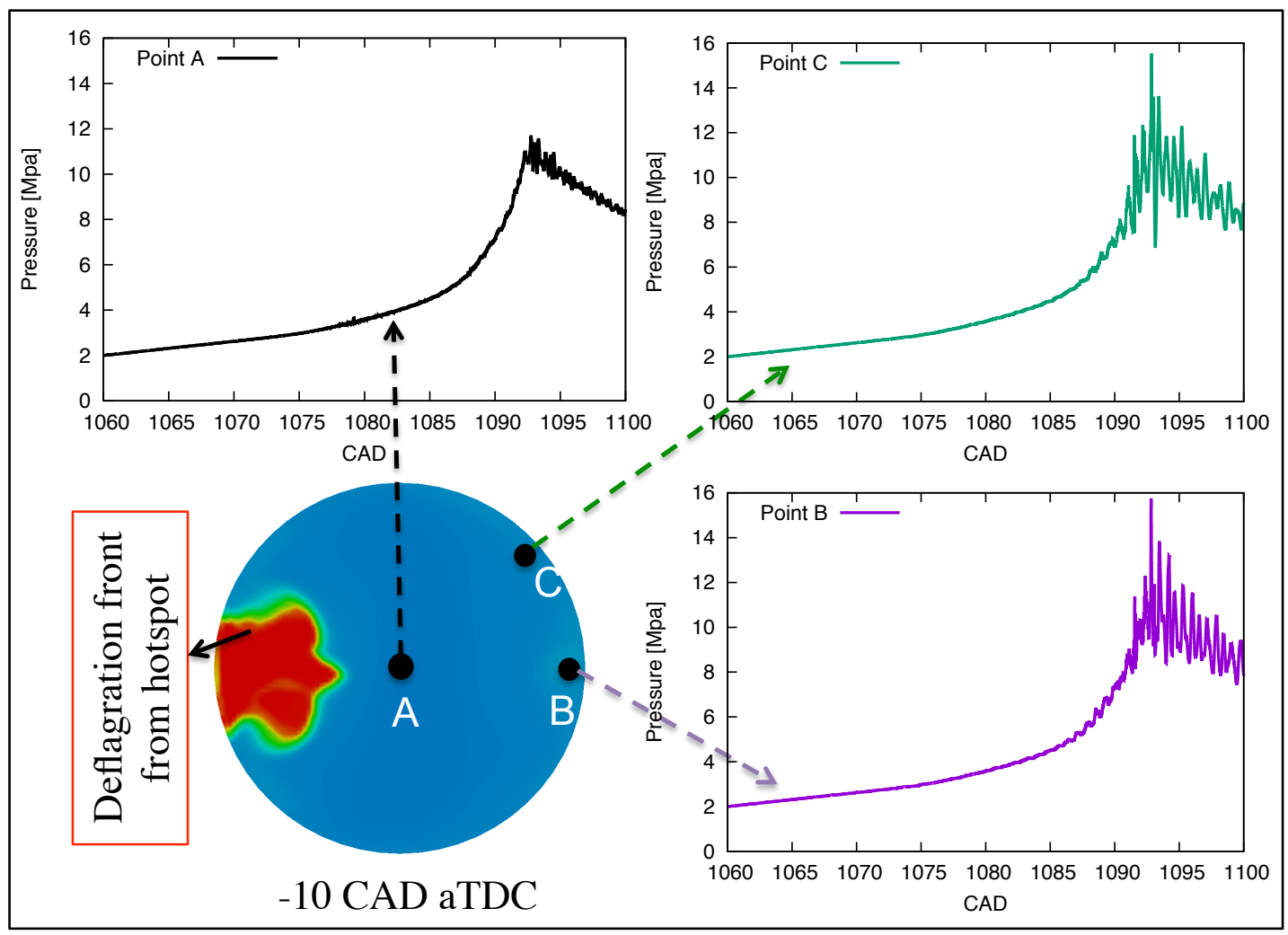

Fig. 2. In-cylinder pressures and locations for points A, B and C, selected for CSP analysis at Z plane (8mm from spark plug).

current study, the following CSP tools were employed: (i) the eigenvalue participation index (EPI) which is a slightly modified version of the time scale participation index (TPI), and measures the absolute contribution (while the TPI measures the relative contribution) of each reaction to the characteristic time scale $[20,21]$ and (ii) the CSP Pointer (CSP Po), which identifies the scalar variables that mostly relate to the dominant CSP mode [22-25]. A reaction with a positive (negative) EPI value favors (opposes) the explosive character of the time scale, therefore it tends to promote (oppose) the ignition process. Moreover, high CSP Po values of the dominant mode identify scalar variables, which have a large impact on the evolution of the process.

For a system of $\mathrm{N}$ scalar variables (species plus temperature), there are a total of $\mathrm{N} \mathrm{CSP}$ modes, for which the basis vectors are approximated by the right and left eigenvectors of the 
Jacobian of the chemical source term [26, 27]. The characteristic time scale for each chemical mode is approximated by $\tau_{n}=\left|\lambda_{n}\right|^{-1}$, where $\lambda_{n}$ is the eigenvalue of the $n$-th CSP mode $(n=1, \ldots, N)$. This kind of analysis is meaningful if there exists a large gap between the time scales of two adjacent modes, which will allow decomposition into fast (or exhausted) and slow (or active) modes. The fastest of the slow time scales, corresponding to the fastest active mode, is the one that characterizes the evolution of the system and the corresponding amplitude the largest of all modes. In homogeneous auto-ignition, the fastest active time scale is usually of explosive nature, and characterizes the action of slow and active chemical processes that drive the system away from equilibrium to result in ignition processes [20, 27].

Therefore, the main objective of the CSP analysis is to first identify the characteristic time scales of explosive nature, and then to explore the important reactions that contribute to their generation. Additional insight is obtained by investigating the scalar variables associated most to the related CSP modes.

The CSP analysis was applied to points A-C shown in Fig. 2 throughout the temporal evolution, which allows to compare flame and super-knock chemistry and identify differences between them. In general, the results of point $\mathrm{B}$ and $\mathrm{C}$ were found to be both qualitatively and quantitatively similar. Consequently, in the following, only the results for point $\mathrm{B}$ will be presented and unless otherwise stated, the conclusions will be representative for both points that exhibit super-knock. The chemical kinetics mechanism that was used includes $\mathrm{N}=48$ species and $\mathrm{K}=152$ reversible reactions and has been validated in a wide range of initial conditions [28]. The top dead center (TDC) of the engine cycle is at $1080 \mathrm{CAD}$ for all figures presented below. 


\section{The Dynamics of the Systems}

The time scales that characterize the dynamics of the spatial points A and B are displayed in Fig. 3, with black solid and red dashed lines representing dissipative and explosive time scales, respectively. As shown in each case, almost all time scales are of dissipative nature except for few (at most two in each case) that are the explosive ones; a fast one and a slow one. In both cases, a time scale gap is generated and the fast explosive time scale $\left(\tau_{\mathrm{e}, \mathrm{f}}\right)$ is among the fastest of the slow time scales. The gap among the time scales suggests that a valid reduced model can be constructed, while the placement of $\left(\tau_{\mathrm{e}, \mathrm{f}}\right)$ suggests that this is the characteristic time scale during the process. In addition, it was found that the amplitude of the fast explosive mode is always much larger compared to the rest, in both cases under examination. Therefore, in the following, the analysis will focus on the reactions that have the largest contribution to $\tau_{\mathrm{e}, \mathrm{f}}$ and on the species that are mostly associated to the related fast explosive mode.

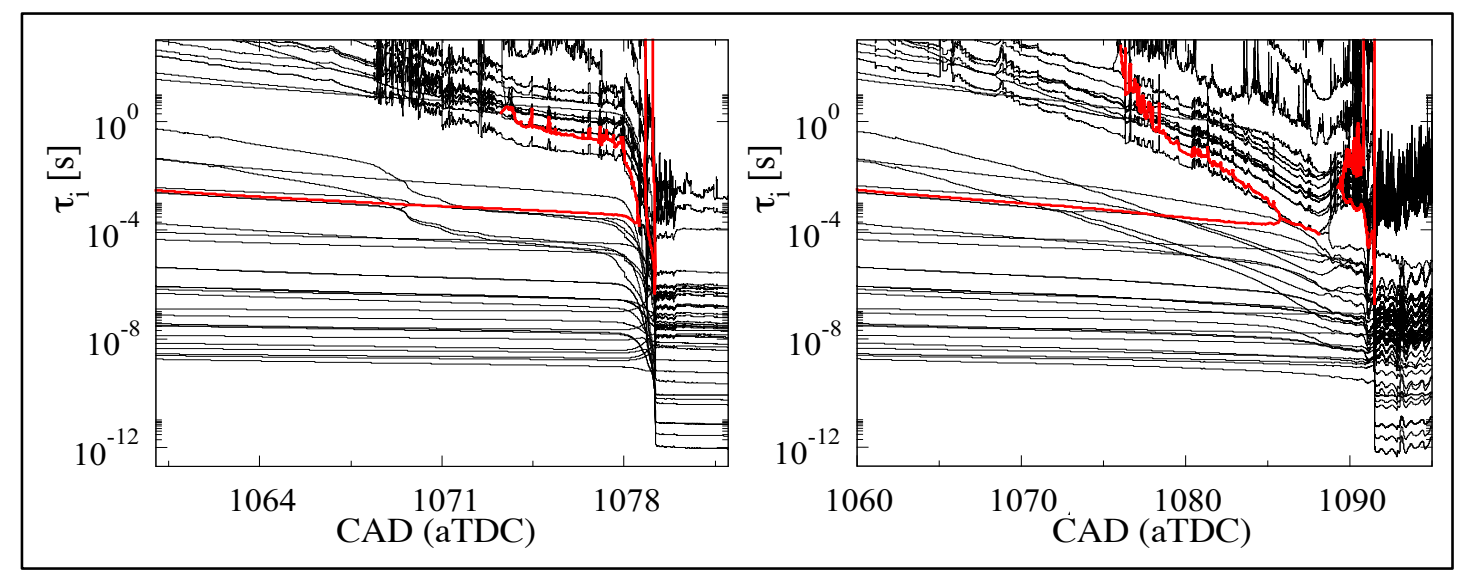

Fig. 3. The developing time scales for point A (left) and point B (right). Solid black and dashed red lines represent dissipative and explosive time scales, respectively.

The evolution of the explosive time scales along with temperature is displayed in Fig. 4 for both spatial points A and B. For a comparison of the CSP diagnostics between the two points, the $\mathrm{x}$-axis has been normalized against the $\mathrm{CAD}$ at the maximum temperature gradient for each point, respectively (1079.18 for point A and 1091.55 for point B). Note that, while both cases 
may appear to represent auto-ignition of the local mixture, the mixture at point A did not undergo auto-ignition but was rather engulfed by the flame propagation. Therefore, the temperature rise shown for point A shows the flame propagation time scale. The temporal points $\left(\mathrm{P}_{1}-\mathrm{P}_{6}\right)$ where the CSP diagnostics will be discussed next are also marked in Fig. 4 for spatial points $\mathrm{A}$ and $\mathrm{B}$.

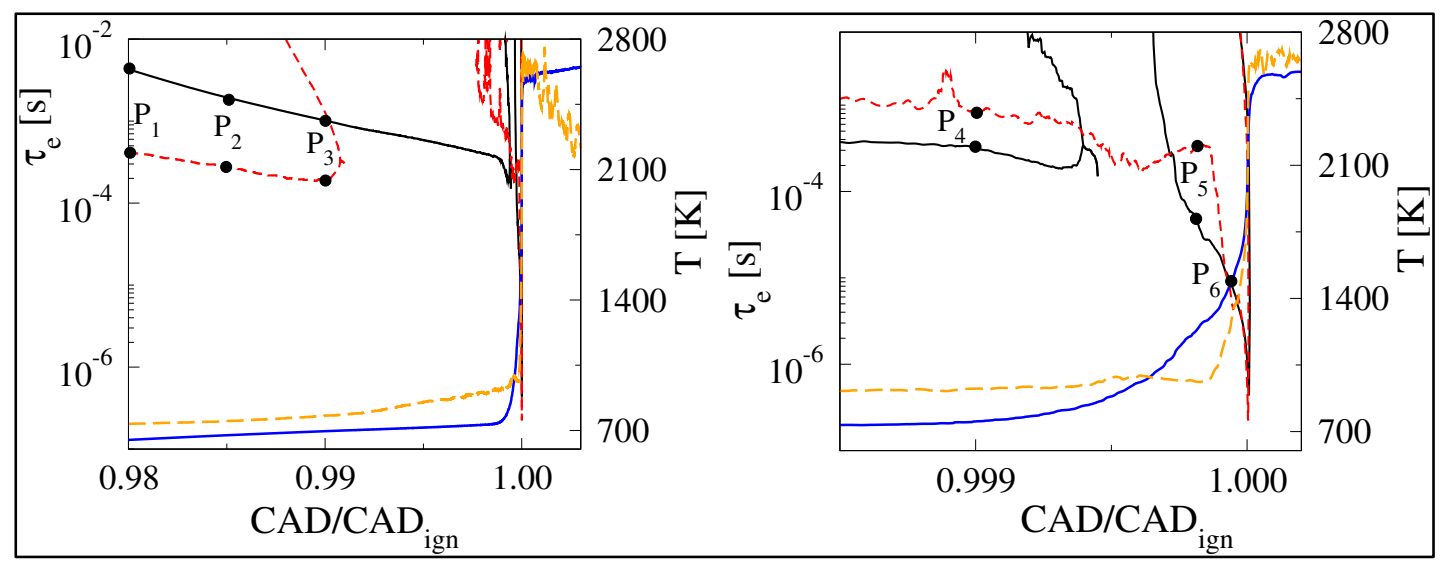

Fig. 4. The developing explosive time scales $\left(\tau_{\mathrm{e}}\right)$ and the temperature evolution for points $\mathrm{A}$ (solid black and blue) and B (dashed red and orange).

Figure 4 reveals that in both cases, a fast explosive time scale initially exists, gradually accelerating and at some point meets a slow one and then both disappear. Briefly afterwards a fast explosive time scale re-appears, accelerating more quickly until it starts to decelerate rapidly, meets a slow explosive time scale and then both disappear. The second merging point is just before temperature reaches its maximum rate of change. The disappearance and reappearance of the fast explosive time scale briefly afterwards is typical of multi-stage ignition $[25,29]$. Therefore, based on the profiles of the explosive time scales, it is concluded that both cases exhibit two-stage ignition chemistry, although the extent of the second stage is much more pronounced for point B. Again, the behavior at point A indicates an early arrival of the flame 
front while the local mixture is undergoing the first stage ignition, and the subsequent second stage ignition chemistry was driven by the flame passing.

Table 2 summarizes all the reactions that were identified as important contributors to the generation of $\tau_{e, \mathrm{f}}$ in both cases under investigation. In the following, the subscripts "f" and " $b$ " stand for forward and backward reaction, respectively. Tables 3 and 4 summarize the CSP diagnostics for points $\mathrm{A}$ and $\mathrm{B}$. For point $\mathrm{A}, \mathrm{P}_{1}-\mathrm{P}_{4}$ belong to the first ignition stage and $\mathrm{P}_{5}-\mathrm{P}_{6}$ to the second, while for point $\mathrm{B}$, first stage is represented by $\mathrm{P}_{1}-\mathrm{P}_{3}$ and second stage by $\mathrm{P}_{4}-\mathrm{P}_{6}$. In both spatial points, the first stage is dominated by the same set of reactions, while their contributions to $\tau_{\mathrm{e}, \mathrm{f}}$ are much more enhanced in point $\mathrm{B}$ due to the higher temperature. Comparison of the results from $\mathrm{P}_{1}$ to $\mathrm{P}_{3}$ shows that the temperature of point $\mathrm{B}$ is increased by approximately $80 \mathrm{~K}$ compared to point A (see Fig. 5(a)). The temperature stratification in the cylinder is the result of temperature drop caused by fuel evaporation during direct fuel injection and heat transfer between the in-cylinder gas and fuel droplets. Furthermore, since point B is located further away near the end wall, the long duration of the flame propagation compresses and heats up the end-gas. Consequently, point B spends much longer time developing radicals through the first stage chemistry at higher temperature, making it highly reactive by the time the mixture enters the second stage of ignition. On the other hand, point A only develops the first stage ignition chemistry for a short period of time at lower temperature; hence its second stage chemistry becomes active only upon the arrival of the flame.

Note also that during the first ignition stage, point B is by approximately $50 \%$ fuel leaner compared to point $\mathrm{A}$. This is attributed to the initial mixture distribution resulting from the large scale flow and mixing, resulting in charge stratification. However, the net chemical reactivity appears to be dominated by the temperature effect. 
Table 2: The reactions providing significant contribution to the generation of the fast explosive timescale $\tau_{\mathrm{e}, \mathrm{f}}$, during the ignition at spatial points $\mathrm{A}$ and $\mathrm{B}$.

\begin{tabular}{|c|l|c|l|c|l|}
\hline 13 & $\mathrm{iC}_{8} \mathrm{H}_{18}+\mathrm{O}_{2} \leftrightarrow \mathrm{C}_{8} \mathrm{H}_{17}+\mathrm{HO}_{2}$ & 34 & $\mathrm{C}_{2} \mathrm{H}_{4}+\mathrm{OH} \leftrightarrow \mathrm{C} 2 \mathrm{H} 3+\mathrm{H}_{2} \mathrm{O}$ & 84 & $\mathrm{HCO}+\mathrm{CH}_{3} \leftrightarrow \mathrm{CO}+\mathrm{CH}_{4}$ \\
\hline 14 & $\mathrm{C}_{8} \mathrm{H}_{17}+\mathrm{O}_{2} \leftrightarrow \mathrm{C}_{8} \mathrm{H}_{17} \mathrm{O}_{2}$ & 52 & $\mathrm{H}+\mathrm{O}_{2} \leftrightarrow \mathrm{O}+\mathrm{OH}$ & 89 & $\mathrm{CH}_{2} \mathrm{O}+\mathrm{H} \leftrightarrow \mathrm{HCO}+\mathrm{H}_{2}$ \\
\hline 15 & $\mathrm{C}_{8} \mathrm{H}_{17} \mathrm{O}_{2} \leftrightarrow \mathrm{C}_{8} \mathrm{H}_{16} \mathrm{OOH}$ & 54 & $\mathrm{H}_{2}+\mathrm{OH} \leftrightarrow \mathrm{H}_{2} \mathrm{O}+\mathrm{H}$ & 91 & $\mathrm{CH}_{2} \mathrm{O}+\mathrm{OH} \leftrightarrow \mathrm{HCO}+\mathrm{H}_{2} \mathrm{O}$ \\
\hline 16 & $\mathrm{C}_{8} \mathrm{H}_{16} \mathrm{OOH}+\mathrm{O}_{2} \leftrightarrow \mathrm{O}_{2} \mathrm{C}_{8} \mathrm{H}_{16} \mathrm{OOH}$ & 64 & $\mathrm{HO}_{2}+\mathrm{OH} \leftrightarrow \mathrm{H}_{2} \mathrm{O}+\mathrm{O}_{2}$ & 93 & $\mathrm{CH}_{2} \mathrm{O}+\mathrm{HO}_{2} \leftrightarrow \mathrm{HCO}^{2} \mathrm{H}_{2} \mathrm{O}_{2}$ \\
\hline 17 & $\mathrm{O}_{2} \mathrm{C}_{8} \mathrm{H}_{16} \mathrm{OOH} \leftrightarrow \mathrm{C}_{8} \mathrm{KET}+\mathrm{OH}$ & 65 & $\mathrm{HO}_{2}+\mathrm{HO}_{2} \leftrightarrow \mathrm{H}_{2} \mathrm{O}_{2}+\mathrm{O}_{2}$ & 97 & $\mathrm{CH}_{3}+\mathrm{O}_{2} \leftrightarrow \mathrm{CH}_{2} \mathrm{O}+\mathrm{OH}$ \\
\hline 18 & $\mathrm{C}_{8} \mathrm{KET} \leftrightarrow \mathrm{C}_{6} \mathrm{H}_{13} \mathrm{CO}+\mathrm{CH} \mathrm{H}_{2} \mathrm{O}+\mathrm{OH}$ & 67 & $\mathrm{H}_{2} \mathrm{O}_{2}(+\mathrm{M}) \leftrightarrow 2 \mathrm{OH}(+\mathrm{M})$ & 98 & $\mathrm{CH}_{3}+\mathrm{HO}_{2} \leftrightarrow \mathrm{CH}_{3} \mathrm{O}+\mathrm{OH}$ \\
\hline 20 & $\mathrm{iC}_{8} \mathrm{H}_{18}+\mathrm{OH} \leftrightarrow \mathrm{C}_{8} \mathrm{H}_{17}+\mathrm{H}_{2} \mathrm{O}$ & 72 & $\mathrm{H}_{2} \mathrm{O}_{2}+\mathrm{OH} \leftrightarrow \mathrm{HO} \mathrm{O}_{2}+\mathrm{H}_{2} \mathrm{O}$ & 99 & $\left.\mathrm{CH}_{3}+\mathrm{H}_{(}+\mathrm{M}\right) \leftrightarrow \mathrm{CH}_{4}(+\mathrm{M})$ \\
\hline 23 & $\mathrm{iC}_{8} \mathrm{H}_{18}+\mathrm{HO}_{2} \leftrightarrow \mathrm{C}_{8} \mathrm{H}_{17}+\mathrm{H}_{2} \mathrm{O}_{2}$ & 77 & $\mathrm{HCO}+\mathrm{M} \leftrightarrow \mathrm{H}+\mathrm{CO}+\mathrm{M}$ & 103 & $\mathrm{CH}_{3}+\mathrm{HO}_{2} \leftrightarrow \mathrm{CH}_{4}+\mathrm{O}_{2}$ \\
\hline 24 & $\mathrm{C}_{8} \mathrm{H}_{17} \leftrightarrow \mathrm{C}_{3} \mathrm{H} 7+\mathrm{C}_{3} \mathrm{H}_{6}+\mathrm{C}_{2} \mathrm{H}_{4}$ & \multicolumn{5}{|l}{} \\
\hline
\end{tabular}

Table 3: Values of the largest EPI and CSP Po of the fast explosive mode for point A. Refer to Fig. 4 for the selected points P1-P6.

\begin{tabular}{|c|c|c|c|c|c|c|c|c|c|c|c|c|}
\hline Point & \multicolumn{2}{|c|}{$P_{1}$} & \multicolumn{2}{|c|}{$\mathrm{P}_{2}$} & \multicolumn{2}{|c|}{$P_{3}$} & \multicolumn{2}{|c|}{$\mathrm{P}_{4}$} & \multicolumn{2}{|c|}{$\mathrm{P}_{5}$} & \multicolumn{2}{|c|}{$\mathrm{P}_{6}$} \\
\hline CAD & \multicolumn{2}{|c|}{1057.6063} & \multicolumn{2}{|c|}{1063.0029} & \multicolumn{2}{|c|}{1068.4015} & \multicolumn{2}{|c|}{1078.1095} & \multicolumn{2}{|c|}{1078.9730} & \multicolumn{2}{|c|}{1079.1356} \\
\hline $\mathrm{CAD} / \mathrm{CAD}_{\mathrm{ign}}$ & \multicolumn{2}{|c|}{0.98000} & \multicolumn{2}{|c|}{0.98500} & \multicolumn{2}{|c|}{0.99001} & \multicolumn{2}{|c|}{0.99900} & \multicolumn{2}{|c|}{0.99980} & \multicolumn{2}{|c|}{0.99995} \\
\hline$\lambda_{\mathrm{e}, \mathrm{f}}[\mathrm{s}]$ & \multicolumn{2}{|c|}{$2.34 \mathrm{E}+02$} & \multicolumn{2}{|c|}{$5.16 \mathrm{E}+02$} & \multicolumn{2}{|c|}{$9.87 \mathrm{E}+02$} & \multicolumn{2}{|c|}{$3.19 \mathrm{E}+03$} & \multicolumn{2}{|c|}{$2.06 \mathrm{E}+04$} & \multicolumn{2}{|c|}{$1.68 \mathrm{E}+05$} \\
\hline$\tau_{\mathrm{e}, \mathrm{f}}[\mathrm{s}]$ & \multicolumn{2}{|c|}{$4.28 \mathrm{E}-03$} & \multicolumn{2}{|c|}{$1.94 \mathrm{E}-03$} & \multicolumn{2}{|c|}{$1.01 \mathrm{E}-03$} & \multicolumn{2}{|c|}{ 3.13E-04 } & \multicolumn{2}{|c|}{ 4.85E-05 } & \multicolumn{2}{|c|}{$5.93 \mathrm{E}-06$} \\
\hline $\mathrm{T}[\mathrm{K}]$ & \multicolumn{2}{|c|}{649} & \multicolumn{2}{|c|}{674} & \multicolumn{2}{|c|}{696} & \multicolumn{2}{|c|}{754} & & & & \\
\hline $\mathrm{y}_{\mathrm{iC} 8 \mathrm{H} 16}$ & & & 6.73 & & 6.57 & & 6.39 & & & & & \\
\hline EPI & $15 \mathrm{f}$ & 94 & $15 \mathrm{f}$ & 210 & $15 \mathrm{f}$ & 411 & $15 \mathrm{f}$ & 1741 & $67 \mathrm{f}$ & 7582 & $52 \mathrm{f}$ & 149324 \\
\hline & $18 \mathrm{f}$ & 89 & $18 \mathrm{f}$ & 195 & $18 \mathrm{f}$ & 369 & $18 \mathrm{f}$ & 1559 & $98 \mathrm{f}$ & 7541 & $98 \mathrm{f}$ & 54529 \\
\hline & $16 \mathrm{f}$ & 68 & $16 \mathrm{f}$ & 161 & $16 \mathrm{f}$ & 328 & $15 \mathrm{~b}$ & -1514 & $52 \mathrm{f}$ & 5843 & $99 \mathrm{f}$ & -41966 \\
\hline & $15 \mathrm{~b}$ & -68 & $15 \mathrm{~b}$ & -161 & $15 \mathrm{~b}$ & -328 & $16 \mathrm{f}$ & 1508 & $13 \mathrm{f}$ & 4897 & $64 \mathrm{f}$ & -40777 \\
\hline & $23 \mathrm{f}$ & 29 & $23 \mathrm{f}$ & 65 & $23 \mathrm{f}$ & 122 & $20 \mathrm{f}$ & 692 & $103 \mathrm{f}$ & -4344 & $77 \mathrm{f}$ & 30166 \\
\hline & $97 \mathrm{f}$ & 14 & $97 \mathrm{f}$ & 35 & $97 \mathrm{f}$ & 56 & $98 \mathrm{f}$ & 418 & $64 \mathrm{f}$ & -3919 & $54 \mathrm{f}$ & 26422 \\
\hline & $17 \mathrm{f}$ & 7 & $17 \mathrm{f}$ & 20 & $17 \mathrm{f}$ & 49 & $91 \mathrm{f}$ & -412 & $93 \mathrm{f}$ & 1913 & $89 \mathrm{f}$ & -25597 \\
\hline & $16 \mathrm{~b}$ & -6 & $16 \mathrm{~b}$ & -17 & $16 \mathrm{~b}$ & -43 & $17 \mathrm{f}$ & 339 & $34 \mathrm{f}$ & 1543 & $84 \mathrm{f}$ & -21505 \\
\hline CSP Po & $\mathrm{C}_{8} \mathrm{H}_{17} \mathrm{O}_{2}$ & 0.42 & $\mathrm{C}_{8} \mathrm{H}_{17} \mathrm{O}_{2}$ & 0.41 & $\mathrm{C}_{8} \mathrm{H}_{17} \mathrm{O}_{2}$ & 0.42 & $\mathrm{C}_{8} \mathrm{KET}$ & 0.49 & $\mathrm{~T}$ & 1.04 & $\mathrm{~T}$ & 1.03 \\
\hline & $\mathrm{C}_{8} \mathrm{KET}$ & 0.38 & $\mathrm{C}_{8} \mathrm{KET}$ & 0.38 & $\mathrm{C}_{8} \mathrm{KET}$ & 0.37 & $\mathrm{C}_{8} \mathrm{H}_{17} \mathrm{O}_{2}$ & 0.48 & $\mathrm{iC}_{8} \mathrm{H}_{18}$ & -0.05 & $\mathrm{O}_{2}$ & -0.07 \\
\hline & $\mathrm{HO}_{2}$ & 0.12 & $\mathrm{HO}_{2}$ & 0.12 & $\mathrm{HO}_{2}$ & 0.13 & $\mathrm{HO}_{2}$ & 0.01 & $\mathrm{H}_{2} \mathrm{O}_{2}$ & -0.04 & $\mathrm{H}_{2}$ & 0.06 \\
\hline
\end{tabular}




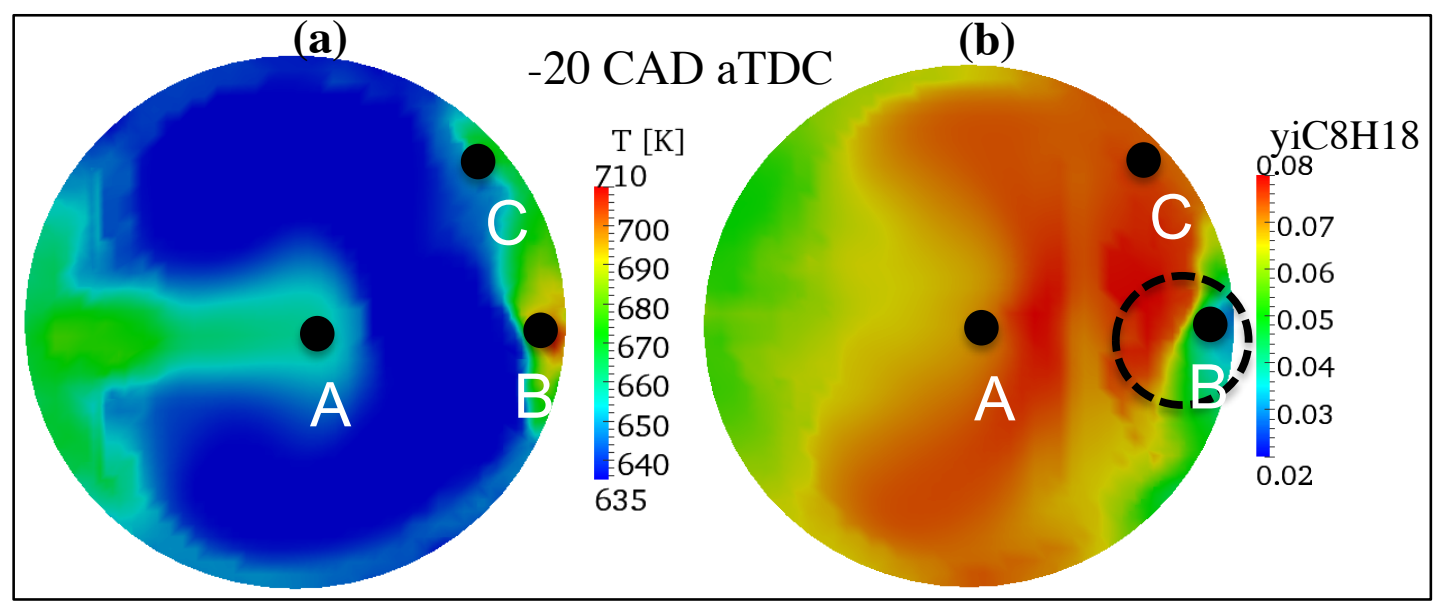

Fig. 5. (a) Initial in-cylinder temperature, (b) iso-octane mass fraction distribution at -20 CAD aTDC (start of deflagration front).

Table 4: Values of the largest EPI and CSP Po of the fast explosive mode for point B. Refer to Fig. 4 for the selected points P1-P6.

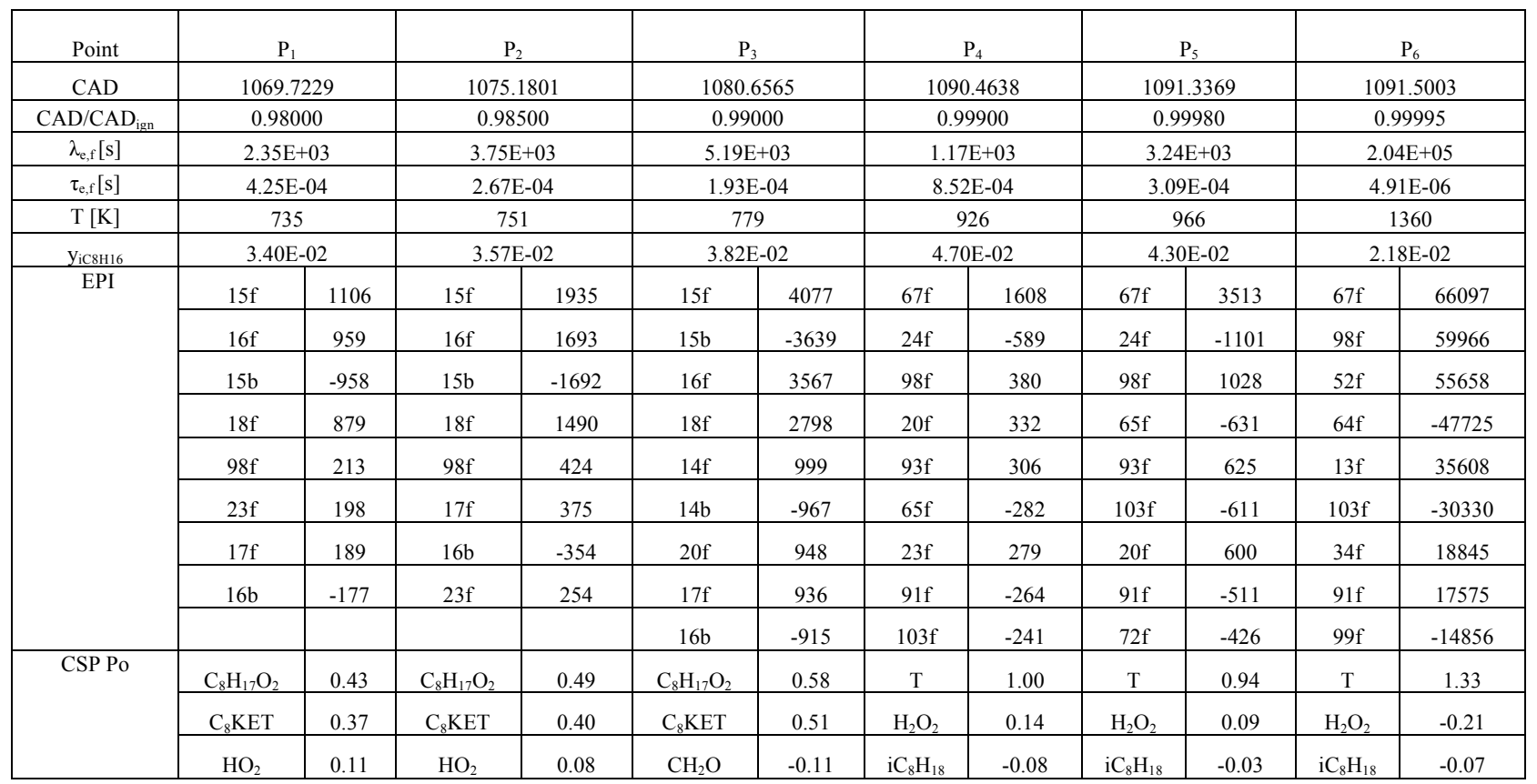

The enhanced reactivity at point $\mathrm{B}$ is highlighted by the fact that its $\lambda_{\mathrm{e}, \mathrm{f}}$ is much larger throughout the entire stage: ten times larger at $\mathrm{P}_{1}$ and five times larger at $\mathrm{P}_{3}$. The EPI values reveal that the largest contributors to $\lambda_{\mathrm{e}, \mathrm{f}}$ during the first stage $\left(\mathrm{P}_{1}-\mathrm{P}_{3}\right)$ in both cases are $15 \mathrm{f}, 18 \mathrm{f}$, $16 \mathrm{f}$ and $15 \mathrm{~b}$, the first three favoring the explosive character of $\lambda_{\mathrm{e}, \mathrm{f}}$, thus, promoting ignition, 
while the last one favors the dissipative character of $\lambda_{\mathrm{e}, \mathrm{f}}$. These reactions compose the typical low-temperature oxidation pathway of iso-octane: $15 \mathrm{f}$ is the isomerization of $\mathrm{C}_{8} \mathrm{H}_{17} \mathrm{O}_{2}$ to $\mathrm{C}_{8} \mathrm{H}_{16} \mathrm{OOH}$, $16 \mathrm{f}$ is the oxidation of $\mathrm{C}_{8} \mathrm{H}_{16} \mathrm{OOH}$ to $\mathrm{O}_{2} \mathrm{C}_{8} \mathrm{H}_{16} \mathrm{OOH}$, $18 \mathrm{f}$ decomposes $\mathrm{C}_{8} \mathrm{KET}$ to products and $\mathrm{OH}$. Reaction $15 \mathrm{~b}$ competes with $16 \mathrm{f}$ and their contributions are practically cancelled. Additional notable positive contributions are provided by $23 \mathrm{f}$ (involving $\mathrm{C}_{8} \mathrm{H}_{17}$ ), 97f/98f (involving $\mathrm{CH}_{3}$ to form $\mathrm{OH}$ ) and $17 \mathrm{f}$ (the low temperature degenerate branching to form $\mathrm{OH})$. At the same time, reaction $16 \mathrm{~b}$ competes with $17 \mathrm{f}$ in the consumption of $\mathrm{O}_{2} \mathrm{C}_{8} \mathrm{H}_{16} \mathrm{OOH}$, but the competition works in favor of $17 \mathrm{f}$. Finally, in both cases, the CSP Po identifies $\mathrm{RO}_{2}$ and $\mathrm{C}_{8} \mathrm{KET}$ as the variables mostly related to the fast explosive mode, while $\mathrm{HO}_{2}$ plays a secondary role.

For point A towards the end of the first stage ignition (e.g., $\mathrm{P}_{4}$ ), the temperature is $25 \mathrm{~K}$ lower and the mass fraction of $\mathrm{iC}_{8} \mathrm{H}_{18}$ is almost two times larger, compared to the respective instant in the super-knock case (e.g., $\left.\mathrm{P}_{3}\right)$. In contrast, at point B (50 \% leaner to point A) the mass fraction of $\mathrm{iC}_{8} \mathrm{H}_{18}$ gradually increases during the first stage due to strong local mass fraction gradients, incurring rapid diffusion of fuel in the neighboring mixture (see Fig. 5(b) circled region). Fig. 6 shows the evolution of the mass fraction of $\mathrm{iC}_{8} \mathrm{H}_{18}$ for points $\mathrm{A}$ and $\mathrm{B}$ with $\tau_{\mathrm{e}, \mathrm{f}}$ overlaid. It is shown that the instant when $\tau_{\mathrm{e}, \mathrm{f}}$ disappears in the point $\mathrm{B}$ case, $\mathrm{y}_{\mathrm{iC} 8 \mathrm{H} 18}$ reaches a local maximum and after that it decreases due to decomposition of $\mathrm{iC}_{8} \mathrm{H}_{18}$. However, its brief decrease is followed by an unexpected increase during which $\tau_{\mathrm{e}}$ reappears but with larger values. The fuel is eventually consumed when $\tau_{\mathrm{e}, \mathrm{f}}$ starts its final steep acceleration. This behavior is distinctly different from point $\mathrm{A}$ where the reappearance of $\tau_{\mathrm{e}}$ is accompanied by a rapid consumption of the fuel. 


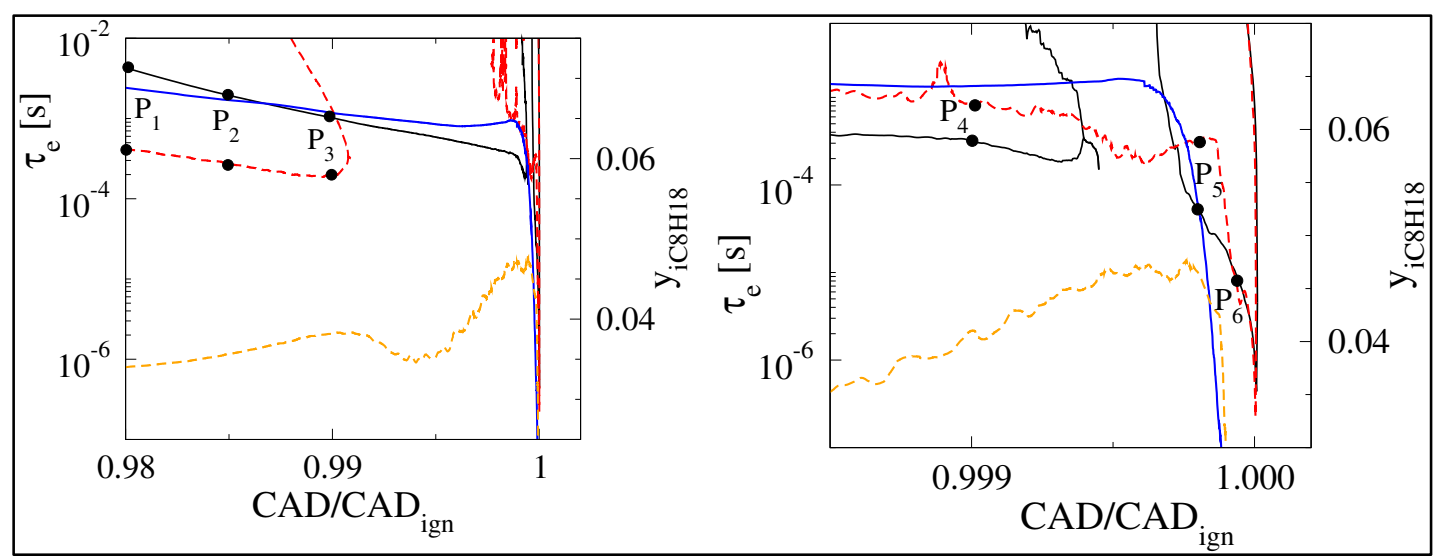

Fig. 6. The developing explosive time scales $\left(\tau_{\mathrm{e}}\right)$ and $\mathrm{y}_{\mathrm{iC} 8 \mathrm{H} 18}$ evolution for points 1 (solid black and blue) and 3 (dashed red and orange).

These results suggest that point B would probably ignite even earlier if the increase of the fuel after the first stage would not occur, since the second stage would be shorter and as it will be shown next, it would be dominated by the same set of reactions in both cases. In summary, the second stage of point $B$ is characterized by a period over which $\tau_{e, f}$ is accelerating slowly and its values are larger than the last part of the first stage, followed by a period that is rapidly accelerating leading eventually the system to ignition. On the other hand, point A does not develop the second stage chemistry until the arrival of the flame, which raises the local temperature rapidly and induces a steep acceleration of the second stage ignition chemistry. The CSP diagnostics of point $\mathrm{B}$ at $\mathrm{P}_{4}$ and $\mathrm{P}_{5}$ are representative of the dominant dynamics at the first part of the second stage. Table 4 indicates that the dominant reaction is the chain branching $67 \mathrm{f}$, which decomposes $\mathrm{H}_{2} \mathrm{O}_{2}$ to two $\mathrm{OH}$ molecules, thus promoting ignition.

From the rest of the reactions that have a considerable contribution to $\tau_{\mathrm{e}, \mathrm{f}}$, the following observations can be made: (i) reaction $98 \mathrm{f}$ has a gradually increasing effect, promoting ignition, (ii) reactions $24 \mathrm{f}, 20 \mathrm{f}, 23 \mathrm{f}$ (the first opposing and the other two promoting ignition) which have a contribution of roughly $20 \%$ in total, are related to the consumption of $\mathrm{iC}_{8} \mathrm{H}_{18}$ or $\mathrm{C}_{8} \mathrm{H}_{17}$ and (iii) except for $67 \mathrm{f}$, hydrogen-related chemistry has a very weak effect. The CSP Po identifies 
temperature as the variable mostly related to the fast explosive mode, an indication that these two points fall in the thermal runaway regime. It is noted though, that $\mathrm{H}_{2} \mathrm{O}_{2}$ is also pointed with a notable value, which is a distinct difference compared to point A. Eventually, as Table 4 shows at $\mathrm{P}_{6}, \tau_{\mathrm{e}, \mathrm{f}}$ for point $\mathrm{B}$ is led to a rapid acceleration mainly by the contributions of $67 \mathrm{f}, 98 \mathrm{f}, 13 \mathrm{f}$. Additionally, the chain branching $52 \mathrm{f}$ provides some considerable contribution accelerating the evolution of the system towards ignition.

The contribution of the hydrogen-related $52 \mathrm{f}$ is basically the fundamental difference between point A and B during the second stage, since in the case of point A, reaction $52 \mathrm{f}$ has a considerable contribution at an earlier stage (at $\mathrm{P}_{5}$ in Table 4) compared to point $\mathrm{B}$ where it becomes dominant later (at $\mathrm{P}_{6}$ in Table 4). At the same time, the relative contribution of $98 \mathrm{f}$ to $\tau_{\mathrm{e}, \mathrm{f}}$ is larger for point A but the opposite holds for 67f. Moreover, only reaction 13f, which includes $\mathrm{iC}_{8} \mathrm{H}_{18}$, has a considerable contribution to $\tau_{\mathrm{e}, \mathrm{f}}$ as opposed to point $\mathrm{B}$ where reactions $24 \mathrm{f}$, 20f, $23 \mathrm{f}$ were also identified. Finally, the CSP Po identifies temperature as the variable mostly related to the fast explosive mode, verifying that as in point $\mathrm{B}$, the second stage relates to the thermal runaway regime.

To further validate the above findings as the characteristics of super-knock event, an additional engine simulation was performed at the same operating conditions, but with preignition initiated at $-5 \mathrm{CAD}$ aTDC. The temperature and fuel distribution are comparable to the pre-ignition cycle, as shown in Fig. 7. The same two locations B and C were examined and it 


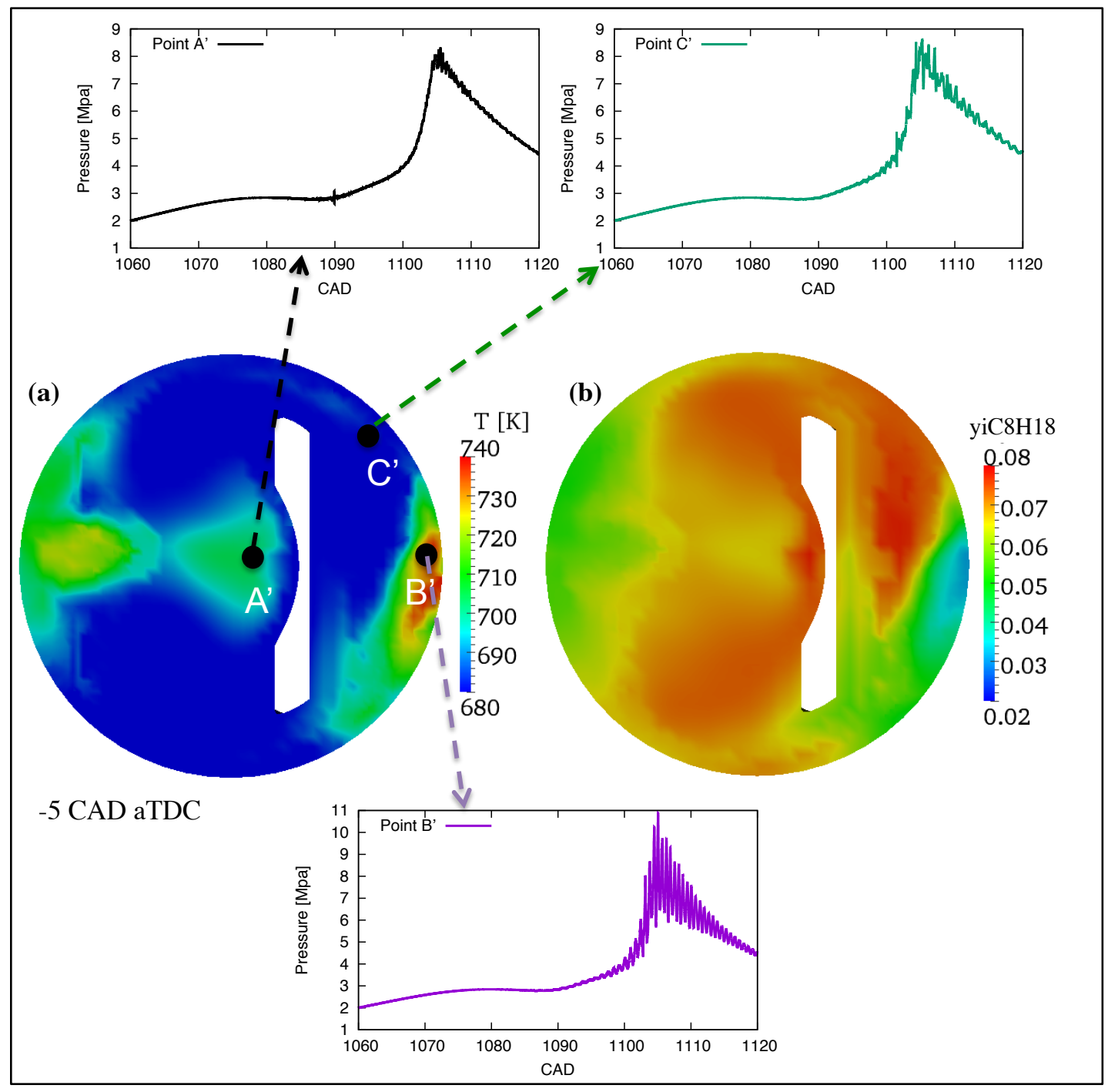

Fig. 7. (a) Temperature (b) iso-octane mass fraction at start of spark timing, pressures at local point $\mathrm{A}^{\prime}, \mathrm{B}^{\prime}$ and $\mathrm{C}^{\prime}$ are shown.

was found that point $\mathrm{C}$ for this case only led to mild knock with a lower pressure peak. Therefore, a CSP analysis was applied to this point, which is referred to as $\mathrm{C}^{\prime}$ in order to distinguish it from point $\mathrm{C}$ in the previous analysis. Details on the CSP diagnostics for this point are provided in Table 5 and Fig. 8.

To highlight the key findings, point $\mathrm{C}^{\prime}$ exhibited a two-stage ignition characterized by a distinct set of explosive time scales, which were more pronounced compared to point $\mathrm{A}$. The 


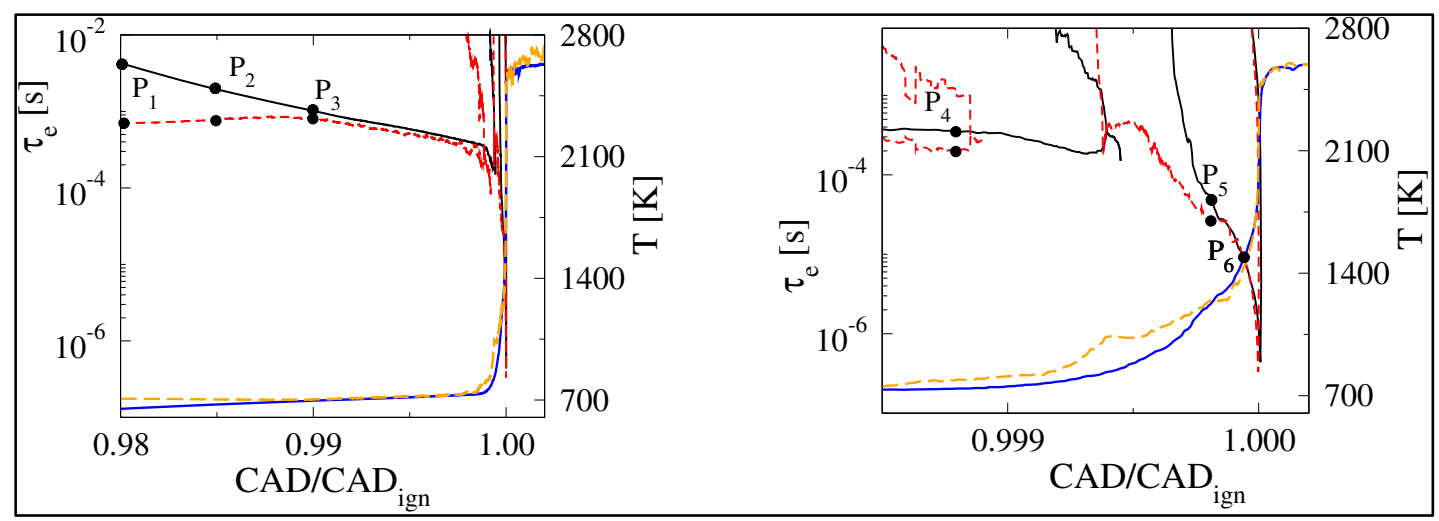

Fig. 8. The developing explosive time scales $\left(\tau_{\mathrm{e}}\right)$ and the temperature evolution for points $\mathrm{A}$ (solid black and blue) and $\mathrm{C}^{\prime}$ (dashed red and orange).

Table 5: Values of the largest EPI and CSP Po of the fast explosive mode for point $\mathrm{C}^{\prime}$. Refer to Fig. 8 for the selected points P1-P6.

\begin{tabular}{|c|c|c|c|c|c|c|c|c|c|c|c|c|}
\hline Point & \multicolumn{2}{|c|}{$\mathrm{P}_{1}$} & \multicolumn{2}{|c|}{$\mathrm{P}_{2}$} & \multicolumn{2}{|c|}{$\mathrm{P}_{3}$} & \multicolumn{2}{|c|}{$\mathrm{P}_{4}$} & \multicolumn{2}{|c|}{$\mathrm{P}_{5}$} & \multicolumn{2}{|c|}{$\mathrm{P}_{6}$} \\
\hline $\mathrm{CAD} / \mathrm{CAD}_{\text {ign }}$ & \multicolumn{2}{|c|}{1079.4468} & \multicolumn{2}{|c|}{1084.9539} & \multicolumn{2}{|c|}{1090.4613} & \multicolumn{2}{|c|}{1100.3751} & \multicolumn{2}{|c|}{1101.2559} & \multicolumn{2}{|c|}{1101.4214} \\
\hline CAD & \multicolumn{2}{|c|}{0.98000} & \multicolumn{2}{|c|}{0.98500} & \multicolumn{2}{|c|}{0.99000} & \multicolumn{2}{|c|}{0.99900} & \multicolumn{2}{|c|}{0.99980} & \multicolumn{2}{|c|}{0.99995} \\
\hline$\lambda_{\mathrm{e}, \mathrm{f}}[\mathrm{s}]$ & \multicolumn{2}{|c|}{$1.42 \mathrm{E}+03$} & \multicolumn{2}{|c|}{$1.30 \mathrm{E}+03$} & \multicolumn{2}{|c|}{$1.24 \mathrm{E}+03$} & \multicolumn{2}{|c|}{$2.90 \mathrm{E}+03$} & \multicolumn{2}{|c|}{$3.83 \mathrm{E}+04$} & \multicolumn{2}{|c|}{$1.35 \mathrm{E}+05$} \\
\hline$\tau_{\mathrm{e}, \mathrm{f}}[\mathrm{s}]$ & \multicolumn{2}{|c|}{$7.05 \mathrm{E}-04$} & \multicolumn{2}{|c|}{$7.72 \mathrm{E}-04$} & \multicolumn{2}{|c|}{$8.05 \mathrm{E}-04$} & \multicolumn{2}{|c|}{$1.93 \mathrm{E}-04$} & \multicolumn{2}{|c|}{$2.61 \mathrm{E}-05$} & \multicolumn{2}{|c|}{$7.40 \mathrm{E}-06$} \\
\hline $\mathrm{T}[\mathrm{K}]$ & \multicolumn{2}{|c|}{707} & \multicolumn{2}{|c|}{704} & \multicolumn{2}{|c|}{703} & & & & & & \\
\hline $\mathrm{y}_{\mathrm{iC} 8 \mathrm{H} 16}$ & $5.72 \mathrm{E}$ & & 5.73 & & $5.84 \mathrm{I}$ & & & & 3.32 & & & \\
\hline EPI & $15 \mathrm{f}$ & 624 & $15 \mathrm{f}$ & 602 & $15 \mathrm{f}$ & 609 & $15 \mathrm{f}$ & 2417 & $67 \mathrm{f}$ & 15778 & $52 \mathrm{f}$ & 95708 \\
\hline & $18 \mathrm{f}$ & 552 & $18 \mathrm{f}$ & 538 & $18 \mathrm{f}$ & 547 & $20 \mathrm{f}$ & 2347 & $98 \mathrm{f}$ & 14417 & $98 \mathrm{f}$ & 46998 \\
\hline & $16 \mathrm{f}$ & 502 & $16 \mathrm{f}$ & 480 & $15 b$ & -483 & $15 b$ & -2229 & $52 \mathrm{f}$ & 9312 & $64 \mathrm{f}$ & -34409 \\
\hline & $15 \mathrm{~b}$ & -502 & $15 b$ & -480 & $16 \mathrm{f}$ & 482 & $16 \mathrm{f}$ & 2205 & $103 \mathrm{f}$ & -8921 & $13 \mathrm{f}$ & 25923 \\
\hline & $23 \mathrm{f}$ & 145 & $23 \mathrm{f}$ & 121 & $23 \mathrm{f}$ & 102 & $18 \mathrm{f}$ & 1492 & $13 \mathrm{f}$ & 7891 & $99 \mathrm{f}$ & -25311 \\
\hline & $98 \mathrm{f}$ & 103 & $98 \mathrm{f}$ & 94 & $98 \mathrm{f}$ & 81 & $91 \mathrm{f}$ & -1478 & $64 \mathrm{f}$ & $\begin{array}{l}-7359 \\
\end{array}$ & $103 \mathrm{f}$ & -21764 \\
\hline & $17 \mathrm{f}$ & 82 & $17 \mathrm{f}$ & 77 & $17 \mathrm{f}$ & 76 & $14 \mathrm{f}$ & 1064 & $93 \mathrm{f}$ & 4743 & $89 \mathrm{f}$ & -19831 \\
\hline & $16 \mathrm{~b}$ & $\begin{array}{l}-74 \\
\end{array}$ & $16 \mathrm{~b}$ & $\begin{array}{l}-68 \\
\end{array}$ & $16 \mathrm{~b}$ & -68 & $14 \mathrm{~b}$ & -1036 & $34 \mathrm{f}$ & 3516 & $77 \mathrm{f}$ & 17662 \\
\hline & $103 \mathrm{f}$ & -40 & $103 \mathrm{f}$ & -53 & $103 \mathrm{f}$ & -59 & $98 \mathrm{f}$ & 963 & $65 \mathrm{f}$ & -2939 & $54 \mathrm{f}$ & 15679 \\
\hline CSP Po & $\mathrm{C}_{8} \mathrm{H}_{17} \mathrm{O}_{2}$ & 0.45 & $\mathrm{C}_{8} \mathrm{H}_{17} \mathrm{O}_{2}$ & 0.47 & $\mathrm{C}_{8} \mathrm{H}_{17} \mathrm{O}_{2}$ & 0.49 & $\mathrm{CH}_{2} \mathrm{O}$ & 0.37 & T & 1.16 & $\mathrm{~T}$ & 1.12 \\
\hline & $\mathrm{C}_{8} \mathrm{KET}$ & 0.39 & $\mathrm{C}_{8} \mathrm{KET}$ & 0.41 & $\mathrm{C}_{8} \mathrm{KET}$ & 0.44 & $\mathrm{~T}$ & 0.26 & $\mathrm{H}_{2} \mathrm{O}_{2}$ & -0.14 & $\mathrm{iC}_{8} \mathrm{H}_{18}$ & -0.07 \\
\hline & $\mathrm{HO}_{2}$ & 0.11 & $\mathrm{HO}_{2}$ & 0.08 & $\mathrm{HO}_{2}$ & 0.04 & $\mathrm{C}_{2} \mathrm{H}_{4}$ & 0.15 & $\mathrm{iC}_{8} \mathrm{H}_{18}$ & -0.06 & $\mathrm{CH}_{2} \mathrm{O}$ & -0.06 \\
\hline
\end{tabular}

temperature at point $\mathrm{C}^{\prime}$ was found to be slightly higher (by 8\%) during the first stage of ignition compared to point $\mathrm{A}$. As in point $\mathrm{B}$, the mass fraction of $\mathrm{iC}_{8} \mathrm{H}_{18}$ gradually increased during the 
first stage and at the early part of the second stage. The CSP diagnostics revealed that the first stage is dominated by the same set of reactions reported for points A and B, although the characteristic time scale is much faster compared to point $\mathrm{A}\left(80 \%\right.$ at $\mathrm{P}_{1}, 60 \%$ at $\mathrm{P}_{2}$ and $20 \%$ at $\mathrm{P}_{3}$ ), an indication of enhanced reactivity. However, $\tau_{\mathrm{e}, \mathrm{f}}$ of point $\mathrm{C}^{\prime}$ (mild knock) is slower compared to point $\mathrm{B}$ (super-knock) (70\% at $\mathrm{P}_{1}, 300 \%$ at $\mathrm{P}_{2}$ and $700 \%$ at $\mathrm{P}_{3}$ ).

As in the super-knock case (point B), the increased reactivity of point $C^{\prime}$ during the first stage of ignition is due to the enhanced role of $15 f, 16 f$ and $18 f$ (approximately six times larger compared to point A). The contribution of $98 \mathrm{f}$ to $\tau_{\mathrm{e}, \mathrm{f}}$ was the one that increased the most (roughly two orders of magnitude at the early part of the first stage), followed by $17 \mathrm{f}$ and $16 \mathrm{~b}$ (more than ten times larger), as it was previously reported in the analysis of point B. On the other hand, the second stage of ignition was found to be dominated by the hydrogen-related chain branching reactions $67 \mathrm{f}$ and $52 \mathrm{f}$, and the $\mathrm{iC}_{8} \mathrm{H}_{18} / \mathrm{C}_{8} \mathrm{H}_{17}$-related reactions were found to have secondary role to $\tau_{\mathrm{e}, \mathrm{f}}$, which is consistent with what was reported for the second stage of point $\mathrm{A}$, but different from the second stage of point B. All these results indicate that the same mechanism drove both the super-knock and the mild-knock cases, with its features being more striking in the superknock case.

\section{Conclusions}

Pre-ignition cycles were simulated introducing a hot spot over the piston to initiate a deflagration front at -20 and -5 CAD of TDC. CSP analysis was performed on locations that exhibited super-knock (points B and C) and mild knock (point $\mathrm{C}^{\prime}$ ) behavior to understand the dominant chemical reactions involved in their ignition and compared to those from a point that is swept by the flame front (point A). 
The comparison between points A and B revealed that both points exhibited two-stage ignition behavior based not only on the profiles of their respective $\tau_{\mathrm{e}, \mathrm{f}}$ but also from the dominant chemical pathways. However, the two-stage ignition is much more pronounced in the superknock related point B compared to point A, since the latter is swept by the flame and the twostage profile is very weak. In both cases, the first/second stage relates to the chemical/thermal runaway regime. In general, the chemical pathways dominating the first stage of both spatial points are the typical pathways that are commonly found in the literature. However, during the first stage, point B is more reactive than point A, due to: (i) the enhanced role of $15 \mathrm{f}, 18 \mathrm{f}$ and $16 \mathrm{f}$ by one order of magnitude; (ii) the increased effect of $98 \mathrm{f}$ by two to three orders of magnitudes; and (iii) the augmented (by 20-30 times) contribution of 17f. These findings are the result of the higher temperature that characterizes point B. Eventually, point B enters the second stage (thermal runaway) earlier than point A, but its fuel mass fraction has increased due to diffusion as a result of local concentration gradients. This event results in the increased role of reactions 24f, 20f, 23f (which include the consumption of $\mathrm{iC}_{8} \mathrm{H}_{18}$ and $\mathrm{C}_{8} \mathrm{H}_{17}$ ), which happens at the expense of the hydrogen-related reactions $67 \mathrm{f}$ and $52 \mathrm{f}$. On the other hand, in the case of point $\mathrm{A}$, the second ignition stage is dominated by hydrogen-related chemistry, and mainly reactions $67 \mathrm{f}$ and $52 \mathrm{f}$ drive the system to ignition.

The analysis of point $\mathrm{C}^{\prime}$ revealed the same characteristics as those observed in the superknock case but quantitatively milder: (i) a less pronounced two-stage ignition occurs; (ii) the temperature is increased as compared to point A but the increase is not as large as for point B; (iii) the fuel mass fraction gradually increases during the first-stage ignition and increases even more before the initiation of the second stage; (iv) the increased reactivity during the first stage is due to the $15 \mathrm{f}, 18 \mathrm{f}, 16 \mathrm{f}, 98 \mathrm{f}, 17 \mathrm{f}$, with the effect of the last two being much more significant 
(especially 98f). However, the second stage was found to be dominated by hydrogen-related chemistry, resembling the dominant pathway of point A and considerably different from the one observed for point B.

The above findings suggest that the reactivity of the system changes significantly in hot spots, being increased during the first stage, but decreased during the early part of the second stage due to the increase of the fuel mass fraction, which is the result of the local concentration gradients. The increased temperature in the hotspots enhances the effect of the typical first-stage ignition pathway, but significantly more noticeable is the increase of the effect of $98 \mathrm{f}$ and $17 \mathrm{f}$.

\section{Acknowledgements}

The work was performed with the funding from King Abdullah University of Science and Technology. The simulations utilized the KAUST supercomputing facility.

\section{References}

[1] P. Leduc, B. Dubar, A. Ranini, G. Monnier, Downsizing of gasoline engine: an efficient way to reduce CO2 emissions, Oil \& gas science and technology, 58 (2003) 115-127.

[2] C. Dahnz, K.-M. Han, U. Spicher, M. Magar, R. Schieß1, U. Maas, Investigations on preignition in highly supercharged SI engines, SAE International Journal of Engines, 3 (2010) 214224.

[3] Z. Wang, H. Liu, T. Song, Y. Qi, X. He, S. Shuai, J. Wang, Relationship between superknock and pre-ignition, International Journal of Engine Research, 16 (2015) 166-180.

[4] D. Bradley, 'Hot spots' and gasoline engine knock, Journal of the Chemical Society, Faraday Transactions, 92 (1996) 2959-2964.

[5] A. Gupta, H. Shao, J. Remias, J. Roos, Y. Wang, Y. Long, Z. Wang, S.-J. Shuai, Relative Impact of Chemical and Physical Properties of the Oil-Fuel Droplet on Pre-Ignition and SuperKnock in Turbocharged Gasoline Engines, in, SAE Technical Paper, 2016. 
[6] M. Kassai, K. Torii, T. Shiraishi, T. Noda, T.K. Goh, K. Wilbrand, S. Wakefield, A. Healy, D. Doyle, R. Cracknell, Research on the Effect of Lubricant Oil and Fuel Properties on LSPI Occurrence in Boosted SI Engines, in, SAE Technical Paper, 2016.

[7] Y. Qi, Y. Xu, Z. Wang, J. Wang, The effect of oil intrusion on super knock in gasoline engine, in, SAE Technical Paper, 2014.

[8] L. Bates, D. Bradley, G. Paczko, N. Peters, Engine hot spots: Modes of auto-ignition and reaction propagation, Combustion and Flame, 166 (2016) 80-85.

[9] M. Jaasim, F.E. Perez, V. Sivasankaralingam, V. Raman, R. Dibble, H. G. Im, Effect of Location and Timing of Hotspots on Superknock during Pre-ignition, in, SAE Technical Paper, 2017-01-0686, 2017.

[10] R.D. Reitz, R. Diwakar, Effect of drop breakup on fuel sprays, in, SAE Technical Paper 860469, 1986.

[11] R.D. Reitz, R. Diwakar, Structure of high-pressure fuel sprays, in, SAE Technical Paper $870598,1987$.

[12] D.P. Schmidt, C. Rutland, A new droplet collision algorithm, Journal of Computational Physics, 164 (2000) 62-80.

[13] P.J. O'Rourke, A. Amsden, A spray/wall interaction submodel for the KIVA-3 wall film model, in, SAE Technical Paper, 2000.

[14] S.M. Aceves, D.L. Flowers, C.K. Westbrook, J.R. Smith, W. Pitz, R. Dibble, M. Christensen, B. Johansson, A multi-zone model for prediction of HCCI combustion and emissions, in, SAE Technical paper, 2000-01-0271, 2000.

[15] M. Raju, M. Wang, M. Dai, W. Piggott, D. Flowers, Acceleration of detailed chemical kinetics using multi-zone modeling for CFD in internal combustion engine simulations, in, SAE Technical Paper, 2012-01-0135, 2012.

[16] Z. Han, R.D. Reitz, Turbulence modeling of internal combustion engines using RNG $\kappa-\varepsilon$ models, Combustion science and technology, 106 (1995) 267-295.

[17] Z. Han, R.D. Reitz, A temperature wall function formulation for variable-density turbulent flows with application to engine convective heat transfer modeling, International journal of heat and mass transfer, 40 (1997) 613-625.

[18] S. Lam, D. Goussis, The CSP method for simplifying kinetics, International Journal of Chemical Kinetics, 26 (1994) 461-486. 
[19] S. Lam, D. Goussis, Understanding complex chemical kinetics with computational singular perturbation, in: Symposium (International) on Combustion, Elsevier, 1989, pp. 931-941.

[20] D.J. Diamantis, E. Mastorakos, D.A. Goussis, H2/air autoignition: The nature and interaction of the developing explosive modes, Combustion Theory and Modelling, 19 (2015) $382-433$.

[21] E.A. Tingas, D.C. Kyritsis, D.A. Goussis, Autoignition dynamics of DME/air and EtOH/air homogeneous mixtures, Combustion and Flame, 162 (2015) 3263-3276.

[22] D.M. Manias, E.A. Tingas, C.E. Frouzakis, K. Boulouchos, D.A. Goussis, The mechanism by which $\mathrm{CH} 2 \mathrm{O}$ and $\mathrm{H} 2 \mathrm{O} 2$ additives affect the autoignition of $\mathrm{CH} 4$ /air mixtures, Combustion and Flame, 164 (2016) 111-125.

[23] E.A. Tingas, D.C. Kyritsis, D.A. Goussis, Ignition delay control of DME/air and EtOH/air homogeneous autoignition with the use of various additives, Fuel, 169 (2016) 15-24.

[24] E.A. Tingas, D.C. Kyritsis, D.A. Goussis, Comparative investigation of homogeneous autoignition of DME/air and EtOH/air mixtures at low initial temperatures, Combustion Theory and Modelling, 21 (2017) 93-119.

[25] E.A. Tingas, Z. Wang, S.M. Sarathy, H.G. Im, D.A. Goussis, Chemical kinetic insights into the ignition dynamics of n-hexane, Combustion and Flame, 188 (2018) 28-40.

[26] E.A. Tingas, D.C. Kyritsis, D.A. Goussis, Algorithmic determination of the mechanism through which H2O-dilution affects autoignition dynamics and $\mathrm{NO}$ formation in $\mathrm{CH} 4 /$ air mixtures, Fuel, 183 (2016) 90-98.

[27] S. Lam, D. Goussis, Conventional asymptotics and computational singular perturbation for simplified kinetics modelling, in: Reduced kinetic mechanisms and asymptotic approximations for methane-air flames, Springer, 1991, pp. 227-242.

[28] Y. D. Liu, M. Jia, M.-Z. Xie, B. Pang, Enhancement on a skeletal kinetic model for primary reference fuel oxidation by using a semidecoupling methodology, Energy \& Fuels, 26 (2012) 7069-7083.

[29] A. Kazakov, M. Chaos, Z. Zhao, F.L. Dryer, Computational singular perturbation analysis of two-stage ignition of large hydrocarbons, The Journal of Physical Chemistry A, 110 (2006) 7003-7009. 